\title{
Teacher-Centered Mentorship as Meaningful Professional Montessori Development
}

\author{
Laura L. Saylor ${ }^{1}$, Ginger Kelley McKenzie², Cathy Cebulski Sacco² \\ ${ }^{1}$ St. Joseph University \\ ${ }^{2}$ Xavier University
}

Keywords: professional development, mindfulness, reflective practice, clinical supervision, Montessori

\begin{abstract}
A real-time, multidimensional, professional-development program that is connected to both practice and school culture was delivered to a group of Montessori teachers with the goal of improving teaching practices and increasing student success by exploring the potential benefits of mindfulness, structured reflective practice, and teacher-centered mentorship (i.e., clinical supervision), A case study of each participant and of the cocreated professional-development learning communities revealed that the program supported teacher growth and efficacy. Four themes emerged from participants' experiences: the importance of mindfulness as a precursor to reflection and mentorship, the creation of communities of trust, the benefits of structure and focus, and the role of supportive accountability in improved practices. The study provides preliminary evidence for the use of multidimensional and teacher-centered professional-development programs to improve teaching practices. The research study has implications for administrators, teachers, and future research.
\end{abstract}

Too often, the professional development (PD) provided to teachers is ineffective and does not result in improved outcomes for their students (Borko, 2004; Desimone, 2009; Rhoton \& Stiles, 2002). This phenomenon is a source of great concern because research shows that effective teaching practices play a pivotal role in student achievement and success (Kim \& Seo, 2018; Rockoff, 2004). Accordingly, it is critical that all teachers experience PD that is highly effective. There is significant evidence that, to be effective, PD must be engaging, reflective, empowering, collectively participatory, and connected to teachers' practices and classrooms (Desimone, 2009; Nolan, Hawkes, \& Francis, 1993). Research indicates that mindfulness, reflective practice, and clinical supervision are components of this type of effective PD (Acheson \& Gall, 2011; Jennings, Lantieri, \& Roeser, 2012; Larrivee, 2008; Nolan et al., 1993; Rodgers, 2002; Roeser, Skinner, Beers, \& Jennings, 2012).

This study was conducted to explore the use of mindfulness, reflective practice, and clinical supervision in a PD program for Montessori Early Childhood and Elementary teachers. The program contains several key components of Desimone's (2009) framework for effective PD: content focus, active learning, coherence, significant duration, and collective participation. Desimone (2009) argued that these components are 
essential for producing positive outcomes from PD experiences. The study also aligns the PD program with Acheson and Gall's (2011) work calling for PD that is "interactive rather than directive, democratic rather than authoritarian, and teacher-centered rather than supervisor-centered" (p. 8).

Given the lack of literature regarding the use of a PD program incorporating the interwoven aspects of mindfulness, reflective practice, and clinical supervision, this study was exploratory in nature; its purpose was to explore teachers' experiences as they progressed through the collaborative, 8-month program. Because teachers' practices matter, effective PD has the potential to improve their practices and the outcomes for their students. In the following sections, we discuss the conceptual foundations for the study, provide an overview of methods, examine the study's findings, and, finally, contemplate the implications of this study's findings for teachers, administrators, PD providers, and education researchers.

\section{Conceptual Foundation}

As individual constructs, mindfulness, reflective practice, and clinical supervision have been widely discussed in the literature for at least the last two decades. However, studies exploring the intersection of these three concepts as a teacher-centered PD model are less prevalent. Employing a teacher-centered PD program featuring mindfulness, reflective practice, and clinical supervision drives the conceptual foundations of the present study.

\section{Teacher-Centered Mentorship}

The term teacher-centered mentorship (TCM) is used in this study as a modification of the well-known term clinical supervision. The term originated in the medical profession, where it has been used for decades to describe a process for improving the specialized knowledge and skills of practitioners. In education, the clinical-supervision process involves observations that are shared with teachers to assist them in examining their own practices and ultimately in continually improving those practices. In this study, teacher-participants were paired and grouped (according to the age levels of the children they taught) so that they could observe one another's teaching. These colleagues could then offer each other a fresh perspective, helping improve both the observed teacher's practice and the experiences of the students (Zhang, Liu, \& Wang, 2017).

This study took place in an independent Montessori school. The school is considered independent as it is not governed by a public system or a religious entity. The project team comprised several researchers, each of whom had comprehensively studied one of the individual constructs. The project team used their specialty areas of expertise to create and deliver the PD program and to conduct this research study. In Montessori classrooms, teachers are trained to observe children and to offer individualized support and coaching for each child. TCM offers teachers the same opportunity, supplying the unique support and coaching each teacher needs. Maria Montessori believed that children in her multiage classrooms formed relationships and served as teachers for one another (Montessori, 1989). This outcome is possible in a TCM model, too: school administrators have as many professional developers as they have teachers.

\section{Literature Review}

\section{Mindfulness}

The last 15 years has seen an explosion in research on the practice and benefits of mindfulness in almost every sector of society; however, there is a limited body of research examining the role of mindfulness in clinical supervision or the PD of educators (Roeser et al., 2012). According to Shea, (2016), the proliferation of mindfulness was pioneered in large part by Jon Kabat-Zinn and his original mindfulness-based stress reduction program to help patients with chronic pain and suffering. Mindfulness practice derives from Buddhist philosophy dating over 2,600 years ago and has been adapted into a secular practice in Western culture (Shea, 2016). 
Mindfulness meditation is the practice of moment-to-moment, nonjudgmental awareness. According to Kabat-Zinn (2013), we can nurture a mindful stance by considering ourselves impartial witnesses and by stepping away from the voice of judgment within us. Mindfulness is a simple yet difficult practice that cultivates one's ability over time to observe the reality of one's existence without avoiding or changing its characterization to fit a personal worldview. Practicing mindfulness can help to quell habitual reactive tendencies (Siegel, 2010). Mindfulness practices include conscious breathing, sitting and walking meditation, awareness of reactions to thoughts and emotions, and light yoga, all of which emphasize nonjudgmental acceptance. In teaching practice, mindfulness can take the form of increasing awareness of one's thoughts and reducing reactions that hurt one's teaching practice. Before teaching, mindfulness may take the form of light yoga or simple conscious breathing. The consistent formal practice creates structural brain changes that positively alter a person's perception of pain or difficulty, which eventually translates into desirable qualities such as increased attention and focus, empathy, and compassion (Davidson et al., 2003; Kabat-Zinn, 2013).

Mindfulness in clinical supervision within the counseling and psychological fields has been shown to enhance the experiences of both supervisor (i.e., mentor) and supervisee (i.e., mentee), both cognitively, through attention and focus, and by cultivating empathy and compassion (Carroll, 2006, 2009). Some benefits of clinical supervision mirror those of mindfulness practice, such as better stress management, increased self-awareness, and greater self-efficacy. Including mindfulness in clinical supervision helps supervisors accept teachers' weaknesses (Dray \& Wisneski, 2011). In the counseling and psychology professions, supervision is a restorative process that may improve teaching performance and reduce burnout in the stressful mental health fields (Bégat, Ellefsen, \& Severinsson, 2005; White \& Winstanley, 2014).

Studies show that the benefits of mindfulness practice for teachers include emotional awareness and self-regulation (Jennings et al., 2012), as well as a calm disposition when dealing with challenging classroom behaviors (Jennings \& Greenberg, 2009; Roeser et al., 2012). These practices may also prepare teachers for authentic reflection and self-assessment, promoting open-mindedness about personal growth without fear of judgment. New research, while preliminary, indicates mindfulness practices may also serve as a restorative process for teachers and may improve their overall disposition and ability to develop a positive rapport with students and to create an engaging learning environment (Flook, Goldberg, Pinger, Bonus, \& Davidson, 2013; Frank, Reibel, Broderick, Cantrell, \& Metz, 2013; Roeser et al., 2012, Roeser et al., 2013).

\section{Reflective Practice}

Since the opening of Dr. Montessori's Casa dei Bambini in 1907, the topic of reflective practice in education has commanded the attention of many researchers and theorists who have examined the application and outcomes of reflective practices among teachers and their students (Craig, 2010; DarlingHammond, 2006; Del Carlo, Hinkhouse, \& Isbell, 2010; Dewey, 1910; Rodgers, 2002; Schussler, Stooksberry, \& Bercaw, 2010). Professional reflective practice involves the cyclical and increasingly complex nature of contemplating one's experiences in the context of educational theories. The cyclical practice continues with purposefully and methodically considering educational theories in the context of one's own experience (Furtado \& Anderson, 2012); it represents a deeper, professional reflection that involves carefully describing one's professional thinking to find a pathway to improved teaching practices (Rodgers, 2002).

Professional reflective practice can be viewed as educators' exhaustive study of themselves in the arena of their practice (Meier \& Henderson, 2007). Further, professional reflection for teachers is a frequent piece of PD activity (Moss, Springer, \& Dehr, 2008). Guskey's (2002) definition of PD programs - "systematic efforts to bring about change in the classroom practices of teachers, in their attitudes and beliefs, and in the learning outcomes of students" (p. 381) — clarifies the relationship between reflective practice and PD. Additionally, professional reflection can be a starting point for teachers in conducting their own practical action research to take charge of their own PD (Roberts et al., 2010). Professional reflection has 
been a key component of the recommendations of major national organizations whose missions focus on defining professional standards for educators (Council of Chief State School Officers, 2011; Lieberman \& Miller, 2011; National Board for Professional Teaching Standards, 2002). Moreover, the use of reflective evaluative tools in the development and assessment of teachers is found in independent teacher-evaluation systems and in state standards for educators (Danielson, 2007; Ohio Department of Education \& Ohio Educator Standards Board, 2007; Wilson, Freeman-Loftis, Sawyer, \& Denton, 2012; Wisconsin Department of Education, 2013).

Increased understanding of the various levels of reflective practice can lead to improved assessment of reflective practices. The improved assessment, in turn, provides a better chance for educators to move through the series of levels, push themselves out of their comfort zones, and become better teachers who create learning environments of inquiry (Rodgers, 2002). In her 2008 article, Larrivee described the development of an assessment tool "that could be used to establish the level of reflection engaged in by a teacher candidate or a practicing teacher [and to] develop intervention strategies to facilitate movement towards higher levels of reflection" (p. 358). Through her research, Larrivee developed the Survey of Reflective Practice as an instrument for assessing the development of reflective practices. The survey identifies four distinct levels of reflective practice: prereflection (i.e., interpreting teaching situations without thoughtful association to other contexts), surface reflection (i.e., examining teaching methods, limited to how best to achieve scripted objectives), pedagogical reflection (i.e., thinking frequently about how to improve teaching practices to make the best possible impact on students' learning), and critical reflection (i.e., engaging in ongoing reflection and critical inquiry concerning teaching actions as well as thinking processes; Larrivee, 2008).

\section{Clinical Supervision or Teacher-Centered Mentorship}

A review of research on clinical supervision or TCM reveals several important points. The term clinical supervision was first applied to the education profession by Morris Cogan in the 1960s while he coordinated the Master of Arts in Teaching program at Harvard University (Pollock \& Ford, 2009). The term clinical is suggestive of a relationship between a supervisor and a teacher in the school setting (Acheson \& Gall, 2011). The goal of clinical supervision, or TCM, is to provide teachers with objective feedback on the entire instructional process. This mentorship helps teachers develop new instructional strategies and classroommanagement skills while increasing awareness of their practice and thus ownership of their continual growth and improvement.

Through clinical supervision (i.e., TCM), new teachers develop the ability to receive feedback from other professionals. Mentor-teachers and supervisors observe and comment on new teachers' challenges and their strategies to resolve them. Through this process, teachers can develop a professional attitude about continuous PD, engaging in self-development as a career-long effort (Acheson \& Gall, 2011). Teachers thereby become aware of their responses to classroom challenges and become more competent.

Researchers have identified several positive effects of clinical supervision. Glickman and Bey (1990) found teachers had an increased ability to reflect on their instruction and use higher-order thinking skills. In addition, collegiality, openness, and communication improved between teachers and supervisors. Acheson and Gall (2011) found teacher retention improved while teacher anxiety and burnout decreased. Additionally, these researchers found teachers had a greater sense of autonomy, personal efficacy, and self-growth. Furthermore, teachers reported an improved attitude toward the supervisory process, and both student achievement and attitude improved (Acheson \& Gall, 2011).

In 1993, a series of six different clinical-supervision case studies, which included a wide range of teachers with varying tenures, revealed positive changes in the productivity and instructional qualities of the teachers involved, regardless of subject or length of experience (Nolan et al., 1993). Their analysis revealed five commonalities: the development of collegial relationships, the ability to address classroom challenges, a reliable and continual supervision process, reflection on actual teaching events, and observations that pro- 
vide an opportunity for improvement. These themes illustrate key considerations of a clinical supervision or TCM model.

\section{Methods}

A case study approach was used to answer several questions.

- How do Montessori Early Childhood and Elementary teachers experience an integrated PD program that contains mindfulness, reflective practice, and teacher-centered mentorship (i.e., clinical supervision)?

- How do the teachers use the new knowledge to improve their teaching?

- Do the teachers believe they improve their teaching practices as they participate in the PD program containing mindfulness, reflective practice, and teacher-centered mentorship (i.e., clinical supervision)?

Because there is a dearth of research exploring the intersection of mindfulness, reflective practice, and clinical supervision as a TCM PD model, this program represented a unique, bounded case (Yin, 2013) that focused on participants' experiences in their respective communities as the unit of study. This bounded case allowed us to investigate, where the context and phenomenon are somewhat blurred, participants' lived experiences during the integrated PD program (Yin, 2013).

The context for the case was an 8-month-long PD program at an independent Montessori school in an economically and racially diverse Midwestern suburb that enrolls approximately 100 students from preschool through sixth grade. The school is affiliated with the American Montessori Society and adheres to Montessori philosophy and practices, including grouping the children in the same classrooms according to the following age guidelines: 3-6 (preschool and kindergarten), 6-9 (Elementary), and 9-12 (also Elementary). The study included three Elementary teachers and two preschool/kindergarten teachers. All were employed at the school and, highly encouraged by the head of school, opted for enrollment in this PD program. Only one teacher (at the Elementary level) opted out of the program. She was enthusiastic about the program, according to the head of school, but could not participate for personal reasons. The preschool and kindergarten teachers were relatively new to one another, while the Elementary teachers had been teaching together for several years. The study took place in the school, and most meetings and observations occurred in participants' classrooms. Teachers could stop participating in the PD program or research study at any time without penalty.

Before the school year began, we delivered the PD program, which contained detailed plans for the academic year (see Appendix A). The PD program began with a half-day retreat during which we used description, conversation, and activities to introduce participants to mindfulness, reflective practice, and clinical supervision. At the end of the retreat, we provided additional resources and a specially created website where participants could access retreat materials. Early in the school year, we asked participants to choose a practice from a list of mindfulness practices and to complete a survey that helped them identify their level of reflective practices according to Larrivee's (2008) Survey of Reflective Practice, which identifies four distinct levels of reflective practice. We also introduced the participants to the Framework for Teaching (Danielson, 2013) for reflecting on and assessing their own practices. The framework is a "research-based set of components of instruction, aligned to the InTASC [Interstate Teacher Assessment and Support Consortium] standards, and grounded in a constructivist view of learning and teaching" (Danielson Group, 2018). The InTASC standards are a set of ideal core teaching standards that specify the knowledge and abilities teachers should have.

In late October, we held an additional PD session to expand participants' emerging skills in implementing mindfulness and reflective practice. Learning experiences included strategies for becoming more compassionate toward themselves and guided practice with the Survey of Reflective Practice (Larrivee, 
2008) and the Framework for Teaching (Danielson, 2013). In the following weeks, we grouped the participants according to the ages of the children they taught so that they could mentor one another. We observed and supported the participant groups as they employed the TCM protocol that provided them with a clear sequence for addressing growth areas and improving practices (see Appendix B).

In January, we provided additional resources to the participants (i.e., teachers enrolled in the PD program) in all three areas of the PD program through an additional faculty meeting and new resources on the website. Participants continued their efforts in mindfulness activities and reflective practices. In February, we asked participants to identify new or continuing areas of growth using the research-based framework. Once again, we observed and supported participants in their use of TCM using the same protocol used during the first semester.

To provide evidence for the teachers' experiences in the TCM PD program, we collected data on teacher-participants throughout the academic year via quick writes, check-in survey questions, and researcher observations. We adopted quick writes from learning theory that posits the strategy as an activator of students' knowledge that requires students to informally and quickly discuss a given topic (Green, Smith, \& Brown, 2007; Nunan, 2003). This activation of students' knowledge, combined with the strategy's ability to serve as a formative assessment to ascertain increased understanding (Bass, 2003), allowed the quick writes to serve as both professional learning for the teacher-participants and as a data set for the professionaldevelopment programmers. We administered three quick-write sessions in which the teacher-participants answered a series of questions about their understanding of teacher-centered PD, including experiences with mindfulness, reflective practice, and clinical supervision. We conducted these quick writes just prior to the start of the program (i.e., at the beginning, middle, and end of the academic year; see Appendix C).

In addition, we asked the participants to answer a set of check-in questions during each week of the program (see Appendix D). These questions were used to keep the teachers focused on the PD program. Check-in questions ascertained the frequency of the practices in the three areas of the program by asking the participants to indicate on a scale ranging from never to always the extent to which they engaged in the practices. The responses also served as a data set representing our understanding of the participants' firsthand experiences.

Lastly, we observed the participants throughout the PD program. We recorded observation narratives on an open-ended form that tracked activities and conversation and also allowed for later memos, codes, and theme development (see Appendix E). The observation notes also created a narrative of professionaldevelopment interactions for the individual participants, as well as for the professional communities they formed. We completed member checks to gather participant feedback on the written narratives and to validate our participants' experiences (Lincoln \& Guba, 1985). We accomplished this by sharing the written narratives with the participants to confirm and clarify their lived experiences with the PD program. Further, by creating and maintaining a strong participant-researcher relationship, these member checks established a high degree of trustworthiness in the study's data set (Carlson, 2010).

We used quick writes, check-in survey responses, and observation data to create vignettes for each participating teacher. We then used a process of inductive coding and pattern coding to analyze these vignettes from the perspective of the communities they formed during the PD program (Miles, Huberman, \& Saldana, 2013) to identify emergent themes. Inductive coding let us review all the data to understand and organize participants' perspectives and experiences. To find themes, we examined the discovered codes for patterns of shared experiences among the participants.

\section{Findings}

The purpose of the study was to explore the use of three interrelated aspects of a PD program for Early Childhood and Elementary Montessori teachers: TCM (i.e., clinical supervision), mindfulness, and reflective practice. The study focused on teachers' experiences as they used the tools and strategies included in 
the PD program. We taught participants about the benefits of mindfulness and the impact of spending just 5 to 10 minutes a day in a mindful state through an activity contained within a list of mindfulness activities (see Appendix F). In the domain of reflective practice, we trained participants how to use the Survey of Reflective Practice (Larrivee, 2008), mind-mapping strategies, the Framework for Teaching (Danielson, 2013), and resources for evidence-based practices. In the TCM domain, the TCM process involved participating teachers mentoring one another. Therefore, they were explicitly trained in planning initial meetings, developing observable goals, observing each other's practice, and following up with support and suggestions for new strategies that might lead to improved teaching practices and better learning experiences for their students.

The program focused on one key challenge each semester of the program. While we understood that teachers face multiple challenges, focusing on one challenge let us provide strategies for deep learning, including metacognition and critical thought (Hattie, 2013), such as explicit instruction, goal setting, modeling, application, and feedback. This focus on one challenge allowed participants to construct meaning by placing significance on new information, thus creating a deeper learning experience (Biggs \& Tang, 2007).

Many participants gained insight into their own teaching practices, as shown in the individual vignettes below. The vignettes show how participants expressed their evolving PD and how they interacted. Accordingly, a discussion of the PD communities formed follows the individual participant vignettes.

\section{Vignette: Sami}

Pseudonyms have been used to provide anonymity and confidentiality to the participants in this study. Sami was a veteran teacher in one of the school's Elementary classrooms. She felt that the evaluation processes over the course of her career at the school were helpful, particularly in helping her see her strengths and weaknesses. Further, she felt supported in working on the goals set thereon. When asked about her experiences with TCM, she said that she had not heard of that term but that it seemed natural for a Montessori setting.

The tracking survey revealed that her feelings about school varied from week to week. However, she often made time for mindfulness and reflective practice. She said that her responses to children were always peaceful. She also sometimes found it challenging to stay calm. In her middle-of-the-year quick writes, Sami indicated that she valued the specific focus provided by the current PD program and said that focusing on one challenge not only supported her in addressing that challenge but also provided her with a procedure to address other challenges.

Sami received mentoring from Thom, another Elementary teacher at the school. During the first semester, the challenge for Sami was to find a new teaching strategy to increase the active participation of an immature, shy, and reluctant sixth-grade girl. Thom documented her challenge and the observable actions that Sami would take to address it. Sami then put the actions, such as explicit instruction, into her practice. Thom observed and shared his notes with Sami, informing Sami that she was making progress with the student's communication challenges. The mentoring continued into the spring, with Sami adding new practices, such as role play, to support the student's growth. These new practices increased the student's capability to advocate for herself, talk appropriately to her friends, and participate in class discussions.

In end-of-year discussions, Sami said that mindfulness activities helped her view her practices nonjudgmentally. However, she did indicate difficulty in making time for these activities and reiterated her midyear appreciation of focusing on a single, specific challenge for PD:

I am my own worst critic and see so many areas I want to improve in and not enough time to do everything I want to do. By having one challenge, I was able to see and appreciate my growth. I look forward to applying this strategy in my future. 


\section{Vignette: Thom}

Thom was another veteran teacher in one of the school's Elementary classrooms. He described his experience with his administrator during evaluations as fair and helpful. He said that mindfulness was familiar to him because of a workshop he had taken a few years before. He thought reflective practice involved discussing his teaching day with his administrator and coteacher and reported that TCM was a new concept.

Thom also conveyed important information when answering his weekly tracking surveys. His responses revealed that, as for many teachers, some weeks were better than others, and some weeks he had more time to practice focused reflection than others. Data from early in the year revealed that he perceived his reflection skills at the lower prereflection and surface levels. However, as the year progressed, so did his reflection levels, to the higher pedagogical and critical levels.

During the second semester, Thom identified a challenge in working with a student who was not in his classroom but with whom Thom often interacted in the school's Elementary community. This student frequently acted out with other faculty members. Thom was able to reach this student but was challenged by how to support the student's ability to behave appropriately with all faculty members and staff. Thom also saw working with this student as a preventative measure, in that the student was likely going to be in his classroom in the next academic year. Thom, with the support of Kim, the student's classroom teacher, developed a plan of observable actions for him to take with the student, including sitting with him to better understand the triggers that angered or upset him. Thom then asked the student how he could calm himself down.

Kim wrote detailed notes about how Thom supported this student. She mentioned how consistently Thom listened to and acknowledged the student's feelings. By the end of the semester, Thom and the student made an action plan that gave the student a safe place to calm himself down. The student used the new strategy successfully, and his acting-out behaviors decreased.

As the academic year ended, Thom reported that all aspects of the TCM PD program greatly affected his practice, saying that the process was "connected" and "enjoyable." He also commented that, by framing a student's challenge as his own teaching challenge, he grew as a teacher and more progress was made in improving the student's behavior than he had thought possible.

\section{Vignette: Kim}

Kim had been teaching for several years. Kim's initial quick writes indicated that she loved PD, as it "sparks and solidifies" the things she learns as a teacher. She was knowledgeable and enthusiastic about the process of evaluation and appreciated being observed by a mentor who affirmed her strengths and identified areas for improvement. She was somewhat familiar with mindfulness and was very familiar with reflection, which had been part of her work with her school administrator. She did not know exactly what TCM was but thought it might be similar to faculty PD activities used at her school. She said that she liked collaborating with other teachers.

In her weekly tracking surveys, Kim indicated that she had many good teaching weeks. She practiced mindfulness every week of the study except one, when "the classroom had high energy." She indicated that, while she was a novice in its practice, mindfulness helped to "energize" her and helped her to be "a good role model." She practiced tracking reflective thoughts most weeks. Her reflective thoughts remained at the pedagogical level throughout the entire study in that she consistently analyzed the relationship between teaching practices and student learning, sought ways to connect new concepts to students' prior knowledge, and engaged in constructive criticism of her own teaching.

Kim's challenge in the academic year was to improve her practice with a student who consistently did not follow academic or classroom behavioral expectations. After Kim discussed with her mentor, Sami, the strategies she was using, she developed a new set of strategies to support the student. Kim and Sami discussed ways to focus on the student's needs, including attention from Kim and structure from a behavior 
modification protocol that used positive reinforcement. They decided that Kim would meet with the student at the beginning of each day to support her in goal setting. Sami observed that Kim used the heavier modification reinforcements and made contact with the student before and after each classroom transition. She also observed Kim's use of a behavior chart and of home- and school-based incentives. Kim found her new practices with this student so successful that she decided to continue them into the second semester with the same student, supporting her in becoming more successful in her studies and her behavior.

As the academic year ended, Kim felt very positive about the PD program, noting that her positive feelings stemmed from seeing how the changes she made in her practice positively affected a student's behavior, which in turn improved the overall atmosphere in her classroom. She added,

The process helped me know the other teachers better-we had deeper conversations than we normally had. The mentorship gave me a feeling of being built-up. It was also good to have a whole year [of the program] to focus on one child. It helped me be more thoughtful about the activities.

\section{Vignette: Ruth}

Ruth was a first-year teacher in one of the school's preschool and kindergarten classrooms. As such, she started the academic year without experience with evaluation processes as a practicing teacher. Additionally, she had not had any experiences with PD activities. However, Ruth had had prior experiences with mindfulness and reflective practice. The idea of TCM was new to her, and her reaction to it was largely positive.

Throughout the academic year, Ruth indicated through the tracking survey frequently feeling good about her school week. She often felt best about her week when she practiced mindfulness and reflected on her practice using Danielson's (2013) Framework for Teaching. In the middle of the academic year, Ruth said that the current PD was different than she had expected. Before becoming a teacher, she had he had heard that PD involved long meetings on a topic that may or may not be relevant to a teacher's current classroom. She liked that this PD was "self-directed" and that it applied to "the needs of the classroom at that current moment."

Ruth was mentored by Carol, another preschool and kindergarten teacher at the school. During the first semester, Ruth's challenge was to support a child who avoided work during work time. The child not only avoided work, but he also avoided talking about it with Ruth. Carol asked probing questions to better understand Ruth's challenge and took careful notes. The two discussed possible solutions and created a plan to address the child's work avoidance, which Carol observed Ruth put into practice. In a follow-up meeting, Ruth felt more successful and said that having a colleague hold her accountable for a new teaching practice proved helpful in addressing her challenge.

By the end of the academic year, Ruth reported that she had had a "great experience" with the practices and processes in the PD program:

In this program, I was instructed to focus on one aspect of my classroom that was a challenge and what could be done to improve it. I used other teachers and some resources that were recommended by those teachers to help me to focus on just one challenge. It was helpful that the program allowed me to focus on what I needed during the semester and work to improve it. It was also nice to have the other preprimary teacher holding me accountable for sticking to my plan of action.

\section{Vignette: Carol}

Carol, while not a first-year teacher, was still a novice and just starting her first year at the school. She also taught in one of the school's preschool and kindergarten classrooms. Her experiences with evaluation processes at her former school consisted of classroom observation and postobservation discussion with a school administrator. Her experiences with PD included book studies and listening to a guest speaker at a faculty meeting. Although she had heard of mindfulness, Carol did not understand it. She had, however, had some experience with mindfulness as a child in dance and yoga classes. She had also had experience 
with reflective practice, primarily during her student teaching. Carol loved the idea of being mentored and was excited about TCM.

The tracking survey revealed some high points in Carol's feelings about her school week. She also indicated some challenging weeks during which her work felt extremely stressful and difficult to manage. The weeks she reported feeling good correlated with the degree to which she had been able to practice mindfulness and reflection activities. Conversely, the more stressful weeks were when she had been unable to practice mindfulness and reflection activities. At the midpoint of the academic year, Carol reported that the TCM program helped her reach out to her peer teacher Ruth for structured, thoughtful support and advice.

Ruth, another preschool and kindergarten teacher at the school, served as Carol's mentor. The challenge for Carol was with a classroom-management issue. She had a student with autism whose behavior was being mimicked by other children in the classroom and causing inappropriate laughter. Ruth listened carefully and empathetically. Carol had already researched a possible lesson and discussed it with Ruth. After the two teachers discussed the issue and the lesson, they created some strategies and Ruth observed the lesson. In a follow-up meeting, Carol said that the lesson had not had the desired effect. The teachers met again, referred to some ideas from a classroom-management expert they had heard at a conference, and made another plan to implement in the second semester. The new plan, which took advantage of the fresh start of the second semester, had better results.

By the end of the academic year, Carol reported that the PD program had allowed her to focus on identifying growth opportunities in her practice and supported her in meeting those challenges and improving her practice. She felt stronger in her ability to stay "present in the classroom and observe" herself in an open and nonjudgmental manner. She also said that the PD program created "a space for mindfulness to occur in order to better focus on the details for later reflection with issues as they pertain to the education of children." She said that the PD program allowed her to be "more present" in reflecting on her own practice and that being more present allowed her to support more positive behaviors in her students.

\section{Professional Development Learning Communities}

In reviewing the data, we clearly observed that, while all teacher-participants had their own experiences with the PD program, their fellow teacher-participants in this program influenced their experiences, especially those they worked most closely with. Accordingly, the vignettes align with the socioconstructivist view that knowledge is constructed through interactions and dialogue with others (Vygotsky, 1978). The influence of shared understandings of fellow teachers largely influenced the professional growth of each participant. Several themes emerged from the data sets that captured the experiences of the cocreated PD communities.

Mindfulness as precursor. All participants appreciated learning how to incorporate mindfulness into their practice. They found that slowing down and practicing mindfulness allowed them to view their own practices nonjudgmentally. They noticed how their own practices might affect student learning and growth. Researcher observation revealed that, even when topics were challenging, participants actively listened to each other, expressed compassion and curiosity, and asked supportive, clarifying questions.

A community of trust. Participants reported feeling more connected to one another and said that each completed segment of the TCM program brought them closer together. They credited this closeness to the trust and relationships they built in the process. This result is consistent with Desimone's (2009) assertion that collective participation is a critical feature of effective PD. We observed the participants construct safe PD communities and create space for new ideas and teaching strategies. This interdependence and the safe spaces encouraged them to have rich and multifaceted discussions about their practices and about how to improve children's progress and growth. 
Structure and focus. Participants reported that having a structure for reflecting on their practice helped them focus on specific challenges in their practice. Identifying an opportunity for growth was influenced by reflecting on their unique teaching situation within a framework that helped define the specific practice targeted for improvement. A specific opportunity for growth or a teaching challenge was sometimes identified for an individual student and at other times in an issue for a group of students. In both cases, structured reflections led to teachers' areas of focus for growth.

Supportive accountability and change. All participants reported that the TCM PD program and their interactions within their communities brought them a supportive accountability that kept them focused on improving their practices and growing as educators. We observed enthusiasm and increased self-efficacy during participants' meetings, as they mentored and challenged one another to think about how their practices affect student growth and learning. All participants in both PD communities were excited to see how their improved practices resulted in perceived improvement in their students.

\section{Results}

The Montessori Early Childhood and Elementary teachers in this study experienced an integrated PD program that contained mindfulness, reflective practice, and TCM (i.e., clinical supervision) in unique ways, with some commonalities. The teachers in this study used new knowledge to improve their teaching by starting with mindfulness practices that allowed them to examine their practice in a nonjudgmental way. By doing so, Sami improved her use of explicit instruction, a structured and direct methodology for teaching academic skills (Archer \& Hughes, 2011). Other teachers in the study improved their implementation of Universal Design for Learning, a way of thinking about teaching that gives all students an opportunity for success. This was evidenced in Thom's and Kim's abilities to provide choices for self-regulation through "personal goal-setting and expectations," Ruth's ability to provide opportunities for engagement through "sustained effort and persistence," and Carol's ability to provide options for executive functions (Meyer, Rose, \& Gordon, 2014). The Montessori teachers in this study believed they improved their teaching practices as they participated in the PD program. Further, the teachers believed they improved their practices, looked forward to using newly discovered tools in their practice, and formed a stronger learning community.

\section{Conclusion}

This research study provides rich evidence that the Montessori Early Childhood and Elementary teachers in the study setting had positive and practice-changing experiences in this integrated PD program. The evidence also demonstrates that we established credibility, transferability, dependability, and confirmability in the qualitative study (Lincoln \& Guba, 1985). The PD program included mindfulness, reflective practice, and TCM. Further, it demonstrated that mindfulness practices layered with structured reflection activities enable teachers to identify appropriate, specific areas of practice improvement through supportive accountability in a nonjudgmental, connected, and safe space. Importantly, the interwoven and meaningful PD program resulted in a depth of inquiry among its participants, revealing positive changes in their perceived reported self-efficacy, improved instructional practices, and perceived success for the students in their classrooms.

Little recent research in teacher PD has been conducted in a Montessori setting. According to the North American Montessori Teachers' Association (2018), there are an estimated 4,500 public and private Montessori schools in the United States. Despite the schools' unique philosophy and pedagogy, teachers in these schools have not been able to use PD programs that are grounded in the context in which they work. Furthermore, mainstream educational research looked at this study's three elements (i.e., mindfulness, reflective practice, TCM) separately and has not considered them as part of an intermingled PD program. Because of the importance of teacher quality and its role in student achievement, the present study provides a window on how teachers experience a PD program composed of mindfulness, reflective practice, and TCM components in a Montessori setting. 
Researchers studying the PD of teachers in non-Montessori settings can also benefit from this study's findings on the potential impact of a meaningful PD program that intertwines the three elements. These researchers may wish to more closely investigate the effects of this type of program to determine its effect on student growth and development. This approach to supporting teachers may also lead to an engaged, empowered, and effective teaching force.

\section{Limitations and Further Research Needs}

The findings of this research study provide some evidence that a meaningful and integrated PD program centered on teachers and their classrooms can have a powerful effect on teachers' perceived efficacy and practices aimed at improving student growth. Nevertheless, it is important to note the limitations of the study's approach. In particular, the small sample size and exploratory nature of the study limit its generalizability. We intend to develop this line of research by gathering data for subsequent iterations of this PD program and incorporating results into future studies. For example, adding third-party observers of classroom practices both before and after the PD program will provide further understanding of the impact of the program on teaching practices. Also, using larger sample sizes and multiple and diverse school settings will provide valuable information about the general effects of this type of PD program. We hope that the findings of this study encourage additional research into the use of multidimensional and teacher-centered PD programs. Further, we look forward to supporting data from quantitative studies of the effectiveness of such programs.

\section{References}

Acheson, K. A., \& Gall, M. D. (2011). Clinical supervision and teacher development: Pre-service and in-service application. Hoboken, NJ: Wiley.

Bass, K. M. (2003). Monitoring understanding in elementary hands-on science through short writing exercises (Doctoral dissertation). University of Michigan. Available from DeepBlue: http://hdl.handle. net/2027.42/123787

Bégat, B., Ellefsen, B., \& Severinsson, E. (2005). Nurses' satisfaction with their work environment and the outcomes of clinical nursing supervision on nurses' experiences of well-being: A Norwegian study. Journal of Nurse Management, 13, 221-230. https://doi.org/10.1111/j.1365-2834.2004.00527.x

Biggs, J., \& Tang, C. (2007). Teaching for quality learning at university: What the student does (3rd ed). Buckingham, England: Open University Press.

Borko, H. (2004). Professional development and teacher learning: Mapping the terrain. Educational Researcher, 33(8), 3-15. https://doi.org/10.3102/0013189X033008003

Carlson, J. A. (2010). Avoiding traps in member checking. The Qualitative Report, 15, 1102-1113. Retrieved from http://nsuworks.nova.edu/tqr/vol15/iss5/4

Carroll, M. (2006). Key issues in coaching psychology. The Coaching Psychologist, 2(1), 4-8.

Carroll, M. (2009). From mindless to mindful practice: On learning reflection in supervision. Psychotherapy in Australia, 15(4), 40-51. Retrieved from http://emergesupervision.nz/wp-content/uploads/2014/11/ learning reflection.pdf

Council of Chief State School Officers. (2011). InTASC model core teaching standards: A resource for state dialogue. Washington DC: Author.

Craig, C. (2010). Coming full circle: From teacher reflection to classroom action and places in-between. Teachers and Teaching: Theory and Practice, 16(4), 423-435. doi:10.1080/13540601003754814

Danielson, C. (2007). Enhancing professional practice: A framework for teaching (2nd ed.). Alexandria, VA: Association for Supervision and Curriculum Development.

Danielson, C. (2013). The Framework for Teaching: Evaluation instrument. The Danielson Group. Retrieved from http://www.loccsd.ca/ div15/wp-content/uploads/2015/09/2013-framework-forteaching-evaluation-instrument.pdf 
Danielson Group. (2018). The framework. Retrieved from https://www.danielsongroup.org/framework/

Darling-Hammond, L. (2006). Constructing 21st-century teacher education. Journal of Teacher Education, 57(3), 300-314. doi:10.1177/0022487105285962

Davidson, R. J., Kabat-Zinn, J., Schumacher, J., Rosenkranz, M., Muller, D., Santorelli, S. F.,... Sheridan, J. F. (2003). Alterations in brain and immune function produced by mindfulness meditation. Psychosomatic Medicine, 65, 564-570. doi:10.1097/01.PSY.0000077505.67574.E3

Del Carlo, D., Hinkhouse, H., \& Isbell, L. (2010). Developing a reflective practitioner through the connection between educational research and reflective practices. Journal of Science Education and Technology, 19(1), 58-68. doi:10.1007/s10956-009-9178-y

Desimone, L. M. (2009). Improving impact studies of teachers' professional development: Toward better conceptualizations and measures. Educational Researcher, 38(3), 181-199. doi:10.3102/0013189X08331140

Dewey, J. (1910). How we think. Boston, MA: D.C. Heath.

Dray, B. J., \& Wisneski, D. B. (2011). Mindful reflection as a process for developing culturally responsive practices. TEACHING Exceptional Children, 44(1), 28-36. doi:10.1177/004005991104400104

Flook, L., Goldberg, S. B., Pinger, L., Bonus, K., \& Davidson, R. J. (2013). Mindfulness for teachers: A pilot study to assess effects on stress, burnout, and teaching efficacy. Mind, Brain, and Education, 7, 182-195. doi:10.1111/mbe.12026

Frank, J. L., Reibel, D., Broderick, P., Cantrell, T., \& Metz, S. (2013). The effectiveness of mindfulness-based stress reduction on educator stress and well-being: Results from a pilot study. Mindfulness, 6, 208-216. https://doi.org/10.1007/s12671-013-0246-2

Furtado, L., \& Anderson, D. (2012). The reflective teacher leader: An action research model. Journal of School Leadership, 22, 531-568.

Glickman, C. D., \& Bey, T. M. (1990). Supervision. In M. Haberman, \& J. Sikula (Eds.), Handbook of research on teacher education (pp. 549-566). New York, NY: Macmillan.

Green, S. K., Smith, J., III, \& Brown, E. K. (2007). Using quick writes as a classroom assessment tool: Prospects and problems. Journal of Educational Research \& Policy Studies, 7(2), 38-52. Retrieved from ERIC database: https://files.eric.ed.gov/fulltext/EJ809437.pdf

Guskey, T. R. (2002). Professional development and teacher change. Teachers and Teaching: Theory and Practice, 8, 381-391.

Hattie, J. (2013). Visible learning: A synthesis of 800 meta-analyses relating to achievement. New York, NY: Routledge.

Jennings, P. A., \& Greenberg, M. (2009). The prosocial classroom: Teaching social and emotional competence in relation to child and classroom outcomes. Review of Educational Research, 79, 491-525. https://doi.org/10.3102\%2F0034654308325693

Jennings, P. A., Lantieri, L., \& Roeser, R. (2012). Supporting educational goals through cultivating mindfulness: Approaches for teachers and students. In A. Higgins-D’Alessandro, M. Corrigan, \& P. M. Brown (Eds.) The handbook of prosocial education. New York, NY: Rowman and Littlefield. Retrieved from http://www.cincinnatimontessorisociety.org/wp-content/uploads/2017/03/Jennings-LantieriRoeser.2012.pdf

Kabat-Zinn, J. (2013). Full catastrophe living: Using the wisdom of your body and mind to face stress, pain, and illness. New York, NY: Bantam Books.

Kim, K. R., \& Seo, E. H. (2018). The relationship between teacher efficacy and students' academic achievement: A meta-analysis. Social Behavior \& Personality: An International Journal, 46, 529-540. doi:10.2224/sbp. 6554

Larrivee, B. (2008). Meeting the challenge of preparing reflective practitioners. New Educator, 4(2), 87106. doi:10.1080/15476880802014132

Lieberman, A., \& Miller, L. (2011). Learning communities: The starting point for professional learning is in schools and classrooms. Learning Forward. Retrieved from https://learningforward.org/docs/ august-2011/lieberman324.pdf 
Lincoln, Y. S., \& Guba, E. G. (1985). Naturalistic inquiry. Newbury Park, CA: SAGE Publications.

Meier, D. R., \& Henderson, B. (2007). Learning from young children in the classroom: The art and science of teacher research. New York, NY: Teachers College Press.

Meyer, A., Rose, D. H., \& Gordon, D. (2014). Universal design for learning: Theory and practice. Wakefield, MA: CAST Professional Publishing.

Montessori, M. (1989). The child, society and the world: Unpublished speeches and writings. Santa Barbara, CA: Clio Press.

Moss, G., Springer, T., \& Dehr, K. (2008). Guided reflection protocol as narrative inquiry and teacher professional development. Reflective Practice, 9, 497-508. doi:10.1080/14623940802431739

National Board for Professional Teaching Standards. (2002). What teachers should know and be able to do. Arlington, VA: Author.

Nolan, J., Hawkes, B., \& Francis, P. (1993). Case studies: Windows onto clinical supervision. Educational Leadership, 51(2), 52-56.

North American Montessori Teachers' Association. (n.d.). How many Montessori schools are there? Retrieved from http://www.montessori-namta.org/FAQ/Montessori-Education/How-many-Montessorischools-are-there

Nunan, D. (2003). Practical English language teaching. New York, NY: McGraw-Hill.

Ohio Department of Education, \& Ohio Educator Standards Board. (2007). Ohio continuum of teacher development: A resource tool for educators. Columbus, $\mathrm{OH}$ : Author.

Pollock, J. E., \& Ford, S. M. (2009). Improving student learning one principal at a time. Alexandria, VA: Association for Supervision and Curriculum Development.

Rhoton, J., \& Stiles, K. E. (2002). Exploring the professional development design process: Bringing an abstract framework into practice. Science Educator, 11(1), 1-8.

Roberts, S. K., Crawford, P. A., \& Hickmann, R. (2010). Teacher research as a robust and reflective path to professional development. Journal of Early Childhood Teacher Education, 31, 258-275. doi:10.1080/ 10901027.2010 .500557

Rockoff, J. (2004). The impact of individual teachers on student achievement: Evidence from panel data. The American Economic Review, 94, 247-252. Retrieved from http://www.jstor.org/stable/3592891

Rodgers, C. (2002). Defining reflection: Another look at John Dewey and reflective thinking. Teachers College Record, 104, 842-866. doi:10.1111/1467-9620.00181

Roeser, R. W., Schonert-Reichl, K. A., Jha, A., Cullen, M., Wallace, L., Wilensky, R.,...Harrison, J. (2013). Mindfulness training and reductions in teacher stress and burnout: Results from two randomized, waitlist-control field trials. Journal of Educational Psychology, 105, 787-804. http://dx.doi.org/10.1037/ a0032093

Roeser, R. W., Skinner, E., Beers, J., \& Jennings, P. A. (2012). Mindfulness training and teachers' professional development: An emerging area of research and practice. Child Development Perspectives, 6, 167-173. https://doi.org/10.1111/j.1750-8606.2012.00238.x

Schussler, D. L., Stooksberry, L. M., \& Bercaw, L. A. (2010). Understanding teacher candidate dispositions: Reflecting to build self-awareness. Journal of Teacher Education, 61, 350-363. https://doi. org $/ 10.1177 / 0022487110371377$

Shea, C. (2016). A brief history of mindfulness in the USA and its impact on our lives. Psych Central. Retrieved from https://psychcentral.com/lib/a-brief-history-of-mindfulness-in-the-usa-and-its-impacton-our-lives/

Siegel, D. (2010). Mindsight: The new science of personal transformation. New York, NY: Bantam Books. Vygotsky, L. S. (1978). Mind in society: The development of higher psychological process. Cambridge, MA: Harvard University Press.

White, E., \& Winstanley, J. (2014). Clinical supervision and the helping professions: An interpretation of history. The Clinical Supervisor, 33, 3-25. https://doi.org/10.1080/07325223.2014.905226 
Volume 4 (2)

Wilson, M. B., Freeman-Loftis, B., Sawyer, B., \& Denton, P. (2012). Responsive Classroom assessment tool for teachers. Turners Falls, MA: Northeast Foundation for Children.

Wisconsin Department of Education. (2013). Teacher standards. Retrieved from http://tepdl.dpi.wi.gov/ resources/teacher-standards

Wyatt, L. (2011). The role of mindfulness in clinical supervision (Doctoral dissertation). University of North Carolina at Greensboro. Available from NC DOCKS: https://libres.uncg.edu/ir/uncg/listing.aspx?id=7546

Yin, R. K. (2013). Case study research: Design and methods. Thousand Oaks, CA: SAGE.

Zhang, S., Liu, Q. T., \& Wang, Q. Y. (2017). A study of peer coaching in teachers' online professional learning communities. Universal Access in the Information Society, 16, 337-347. https://doi.org/10.1007/ $\underline{\text { s10209-016-0461-4 }}$ 
Appendix A

Professional Development Yearly Plan

\begin{tabular}{|c|c|}
\hline August & $\begin{array}{l}\text { Project team } \\
\text { Collects quick-write data about teacher experiences with evaluation, PD (PD), } \\
\text { and the components of teacher-centered mentorship (TCM) PD program } \\
\circ \text { Conducts learning experiences and practice with reflective practice, mindfulness, } \\
\text { and TCM (i.e., clinical supervision) }\end{array}$ \\
\hline September & $\begin{array}{l}\text { Participants begin weekly work including: } \\
\circ \quad \text { View and absorb resources on Danielson framework } \\
\circ \quad \text { Practice from menu of mindfulness practices } \\
\circ \text { Mentally track levels of reflective practice } \\
\circ \text { Respond to weekly surveys }\end{array}$ \\
\hline October & $\begin{array}{l}\text { - Project team } \\
\circ \text { Conducts learning experiences and practice with reflective practice, mindfulness, } \\
\text { and TCM (clinical supervision) (including role play) } \\
\circ \quad \text { Leads teachers in conducting self-evaluation of instructional domains in Daniel- } \\
\text { son framework }\end{array}$ \\
\hline November & $\begin{array}{l}\text { - Project team } \\
\circ \quad \text { Observes and supports TCM coaching during initial TCM meeting using form } \\
\text { that assures following sequence and outcomes } \\
\circ \quad \text { Observes and supports TCM coaching during follow-up TCM meeting using } \\
\text { form that assures following sequence and outcomes }\end{array}$ \\
\hline December & $\begin{array}{l}\text { - Project team } \\
\text { O Collects quick-write data about teacher experiences with evaluation, PD and the } \\
\text { components of TCM PD program }\end{array}$ \\
\hline January & $\begin{array}{l}\text { - Project team } \\
\quad \text { Conducts learning experiences and practice with reflective practice, mindful- } \\
\text { ness, and TCM (i.e., clinical supervision) }\end{array}$ \\
\hline February & $\begin{array}{l}\text { - Project team } \\
\circ \quad \text { Observes and supports TCM coaching during initial TCM meeting using form } \\
\text { that assures following sequence and outcomes. } \\
\circ \quad \text { Observes and supports TCM coaching during follow-up TCM meeting using } \\
\text { form that assures following sequence and outcomes. }\end{array}$ \\
\hline March & $\begin{array}{l}\text { - Project team } \\
\circ \text { Collects quick-write data about teacher experiences with evaluation, PD, and } \\
\text { the components of TCM PD program } \\
\circ \text { Conducts data verification with participants }\end{array}$ \\
\hline
\end{tabular}




\section{Appendix B}

Checklist for Teacher-Centered Mentorship

\section{TEACHER-CENTERED MENTORSHIP/CLINICAL SUPERVISION CHECKLIST}

Professional Development

2016-2017

Facilitators:

(Circle name of your facilitator.)

Your Name as Mentee:

(Please print)

Name of your Mentor:

(Please print)

Print the date each semester you turn this in:

Each classroom will turn in two forms for each teacher to your facilitator and keep one for yourself since each teacher will be a mentor and a mentee (this will happen each semester).

Goal of TCM/CL: The Goal is the practice of positive professional development of the practicing Montessori teacher. During this year the teachers will learn and practice "mindfulness" and "reflective practice" in order to support the teachers involved with "teacher centered mentorship/clinical supervision". To help the teachers and the facilitators' better support and understand the teaching qualities of each teacher in this professional development program, both the teachers and facilitators for each group of teachers will use Charlotte Danielson's Domain 3 "Instruction" found in the "Framework for Teaching Evaluation Instruction 2013 Edition".

Reminders: (1) Your facilitators will email or phone the teachers she will be supporting this year to set up the date in late Oct. she will be observing in your classroom for 2 hours to fill out the Danielson's Domain 3 "Instruction" checklist. (2) Your facilitator will set up an end of school day meeting in early Nov. (and early March) with her teachers in order to be present in your \#1 Meeting listed in item \#6 below. (3) The facilitator will be present (Mid November and Mid March) for the two hours on two separate days (unless one TCM can be done in the morning and second TCM can be done in the afternoon of the same day as listed in item \#8 below. Two hours on one day for first Mentee and two hours on a second day for the second Mentee (unless both can be done on the same day. One in the morning and one in the afternoon). (4) Final meeting for items \#9 and \#10 will be in late November or early December (late March or early April 2017) with the facilitator present at the end of your school day. (5) In December 2016 during an all staff meeting after school (4:00 to 5:30) the teachers will again fill out "Quick Writes" about teacher experiences with evaluation/PD and the components of pd program. (The third time the teachers will fill out the "Quick Writes" will be in March 2017.) 
Check the appropriate answers to the following questions. Make a copy of these forms for yourself and give your facilitator a copy of each form. (Two forms from each participant due November 2016 and March 2017.)

1. Yes___ No___ First semester 2016 I turned this Check List Form into my facilitator on the day in November when my facilitator came to support us setting up our challenge with our mentor. (Second semester 2017 I turned this Check List Form into my facilitator on the day in March when my facilitator came to support us setting up our challenge with our mentor.)

2. Yes__ No___ First semester 2016 I did fill out the Danielson's Domain 3 "Instruction" form during the month of October, after I watched the Video about Danielson's framework found on * This helped me evaluate my teaching skills and helped me pick a challenge I wanted to work on with my Mentor. (Second semester 2017 I did fill out the Danielson's Domain 3 "Instruction" form during the month of February 2017).

3. Yes___No___ My facilitator came in October 2016 to fill out the Danielson's Domain \#3 “Instruction" form. (Second semester 2017 my facilitator did fill out the Danielson's Domain \#3 "Instruction" form during the month of February.)

4. Yes___No____First semester 2016 I have been working on "Reflective Practice" by working on (a) "Surface Practice" skills, (b) "Reflective Practice" skills, and (c) "Critical Practice" skills which all (p. 15) support deliberate pause and purposeful slowing down. (I repeated this Second semester Jan. 2017.)

5. Yes___No___ First semester $2016 \mathrm{I}$ have been cultivating a focused mind (p.6) through mindfulness practices which are roots of caring, compassion, and empathy. (I repeated this Second semester Jan. 2017.)

6. Yes__No____ In November 2016 (Again in Feb. 2017.) the Mentee, the Mentor, and the Facilitator in each classroom will meet together ( $\underline{\text { Called }}$ Meeting \#1), where each Mentee in his/her classroom gave the Mentor his/her observable challenge and listed two to three ways he/she will incorporate new observable methods to solve his/her challenges.

7. Yes__No___Each Mentor (Nov. 2016 \& Feb. 2017) took notes during the Meeting described in \#6 statement above. Then each Mentor takes his/her notes and makes a list of how the Mentee will incorporate new observable methods to solve the challenges.

8. Yes__No___Each Mentor (Nov. 2016 \& Feb. 2017) and his/her facilitator will watch his/her Mentee for 2 hours during November, taking notes (and video taping the experience if he/she wants to and if every child's parent in the video has signed a written approval that his/her child may be video since the videos will not be seen by anyone except the two teachers in the classroom plus the facilitator of this project) about how the Mentee used his/her observable methods to support the mentee's challenges, which were identified during his/her Meeting \#1. 
9. Yes_________ These notes will be copied and shared with the Mentee and the Facilitator before all three individuals meet again (Called Meeting \#2) to talk about how the Mentee feels about his/her successes or continuing challenges. The facilitator is present to support this conversation and will answer any questions the Mentee and Mentor have for the Facilitator. (This will happen in Nov. 2016 and Feb. 2017).

10. Yes___No___ During this Meeting \#2 each Mentee will tell his/her Mentor and facilitator what she/he will add to the plan if something else comes to her/his thoughts or/and the Mentor might also have a suggestion which might help his/her Mentee continue to be successful with the challenge stated in item \# 6 above. The Mentor will take notes during this conversation. (This will happen in Nov. 2016 and March. 2017. The facilitator will be taking notes during these meetings).

Yes__ No___ I have filled out and copied this form (so I will have a copy) and turned it in to my facilitator first semester by Nov. 2016, and second semester by March, 2017. 


\section{Appendix C \\ Prompts for Quick Writes}

Prompts for Quick-Writes

1. Describe your experiences with evaluations (by an administrator in your building) as a professional paid and certified educator (if any).

2. Describe your experiences with professional development (in your most recent school) as a professional paid and certified educator (if any).

3. Describe any professional experiences you have had (if any) with mindfulness in conjunction with professional development as a professional paid and certified educator.

4. Describe any professional experiences you have had (if any) with reflective practice in conjunction with professional development as a professional paid and certified educator.

5. Describe any professional experiences you have had (if any) with Teacher Centered Mentorship (Clinical Supervision) in conjunction with professional development as a professional paid and certified educator. 


\section{Appendix D \\ Weekly Check-In Survey}

Meaningful PD Survey: Weekly Survey for Meaningful PD Participants

What is your name?

How was your week?

1 Extremely stressful and almost impossible to manage.

2

3

4

5

6 Busy, but a "good" busy and very manageable

Did you get a chance to practice the mindfulness activities?

1 Not at all. I will try again next week!

2

3

4

5

6 I did it! I practiced at least 10 minutes a day every day!

Did you get a chance to track your reflective thoughts? (as directed by on audio) ?

1 Not at all this week. I will try again next week!

2

3

4

5

6 I did it! I tracked at least 1 thought per day! 
Appendix E

Observation Instrument

\begin{tabular}{|l|l|l|}
\hline Name & $\begin{array}{c}\text { Observations, activities, } \\
\text { and conversations }\end{array}$ & $\begin{array}{c}\text { Observer memos, codes, } \\
\text { and themes }\end{array}$ \\
\hline & & \\
\hline & & \\
\hline & & \\
\hline & & \\
\hline & & \\
& & \\
\hline
\end{tabular}




\section{Appendix F}

Menu of Mindfulness Activities

Menu of Mindfulness Practices - Choose from these to spend 5-10 minutes a day practicing mindfulness.

Introduction to Activities

- Apps for Teachers

- Strategies for Self-Compassion

- Calm Glitter Jar

- Friendly Wishes

- Self-Compassion Strategies General

- Just Like Me Meditation

- Just Like Me Recording

- Body Scan

- The Guest House

- New Recording

- Evaluate Your Meditation 